\title{
Robot-assisted radical cystectomy with totally intracorporeal neobladder diversion: perioperative, oncologic, and functional outcomes
}

\author{
Qi Gu\#, Jiadong Xia", Aiming Xu", Tongtong Zhang, Zengjun Wang \\ Department of Urology, The First Affiliated Hospital of Nanjing Medical University, Nanjing, China \\ Contributions: (I) Conception and design: Z Wang; (II) Administrative support: Z Wang; (III) Provision of study materials or patients: Q Gu, J Xia, A \\ $\mathrm{Xu}$; (IV) Collection and assembly of data: Q Gu, J Xia, A Xu; (V) Data analysis and interpretation: Q Gu; (VI) Manuscript writing: All authors; (VII) \\ Final approval of manuscript: All authors. \\ "These authors contributed equally to this work. \\ Correspondence to: Zengjun Wang. Department of Urology, The First Affiliated Hospital of Nanjing Medical University, Nanjing, China. \\ Email: zengjunwang@njmu.edu.cn.
}

Background: The use of robot-assisted radical cystectomy (RARC) has increased rapidly in the past decade. However, reports of intracorporeal neobladder diversion remain limited. This article aimed to provide the surgical steps for RARC with totally intracorporeal neobladder diversion and the present perioperative, oncologic, and functional outcomes.

Methods: Between June 2017 and January 2020, RARC with intracorporeal neobladder diversion was performed in 12 male patients. Perioperative variables, pathologic data, early and late complications, urinary continence, potency, and recurrence-free survival were evaluated as outcome measures.

Results: The surgery was successful in all cases without open conversion. The median operative time, estimated blood loss, and postoperative hospital stay were $419 \mathrm{~min}$ (range, 315-640 min), $400 \mathrm{~mL}$ (range, 250-1,200 mL), and 14.5 days (range, 9-25 days), respectively. No positive surgical margins nor lymph nodes were observed. Eleven minor (grades 1 and 2) and one major (grades 3-5) complications were found in the early (0-30 days) period and six minor and one major complications in the late ( $>30$ days) period. The median follow-up time was 13.1 months (range, 5.4-32.0 months), and two patients died due to metastatic disease. At 6 months after surgery, the daytime continence rate was $90.0 \%$, while the nighttime continence rate was $80.0 \%$. Only two patients $(16.7 \%)$ reported capability of potency. The study was limited by a small sample size and short follow-up.

Conclusions: RARC with intracorporeal neobladder is a complex procedure but technically feasible with acceptable oncologic and functional outcomes. Studies with long-term follow ups and increased number of cases and randomized trials are indispensable to assess the potential of this technique.

Keywords: Robot-assisted radical cystectomy; intracorporeal neobladder; urinary diversion

Submitted Jul 08, 2020. Accepted for publication Sep 28, 2020.

doi: $10.21037 /$ tau-20-1075

View this article at: http://dx.doi.org/10.21037/tau-20-1075

^ ORCID: 0000-0002-9337-2094. 


\section{Introduction}

Bladder cancer is the 11 th most commonly diagnosed cancer worldwide, with a clear male predominance, including incidence and mortality. Radical cystectomy with urinary diversion has been the standard treatment for muscle-invasive or selected high-risk non-muscleinvasive bladder cancer failing bladder-sparing therapy (1). Despite the rapidly increasing use of robot-assisted radical cystectomy (RARC) in the past decade (2), reports of intracorporeal neobladder diversion remain limited. An analysis of 935 RARC cases from the International Robotic Consortium registry showed that between 2003 and 2011, neobladder were constructed in 198 cases $(27.7 \%)$; among these, 61 were intracorporeal, representing $6.5 \%$ of the total cases (3). The low frequency of intracorporeal neobladder could be attributed to the technical complexity and early reports indicating longer operative time $(4,5)$. Several techniques have been reported with acceptable perioperative, oncologic, and functional outcomes (6-12).

This paper aimed to provide the surgical steps for RARC with totally intracorporeal neobladder diversion and present the perioperative, oncologic, and functional outcomes. Some findings from the experience of the authors may be helpful for the implementation of intracorporeal neobladder technique.

This article was presented in accordance with the STROBE reporting checklist (available at http://dx.doi. org/10.21037/tau-20-1075).

\section{Methods}

\section{Patients}

This study was approved by the Ethics Committee of the First Affiliated Hospital of Nanjing Medical University (No. 2020-SR-207), and informed consent was obtained from all the patients. All research procedures were conducted in accordance with the Declaration of Helsinki (as revised in 2013). Between June 2017 and January 2020, RARC with intracorporeal neobladder diversion (Video 1) was performed in 12 male patients diagnosed with bladder cancer. Six patients accepted the standard pelvic lymph node dissection (PLND). The indications for intracorporeal neobladder diversion are the same as those for open surgery. The exclusion criteria were as follows: (I) urethral carcinoma or anastomotic margin tumor, (II) chronic inflammatory bowel disease, (III) a history of extensive abdominal surgery, (IV) serum creatinine of $>133 \mu \mathrm{mol} / \mathrm{L}$,
(V) body mass index (BMI) of $>30 \mathrm{~kg} / \mathrm{m}^{2}$, and (VI) severe cardiovascular/pulmonary disease. All patients were diagnosed with muscle-invasive or high-risk non-muscleinvasive bladder cancer through preoperative pathology and image examination. Routine examinations were applied to all patients. In addition, all patients were required to maintain a fluid diet 2 days before surgery. Fasting was performed for bowel preparation 1 day before surgery, and parenteral nutrition was provided. A cleansing enema was performed 1 day before surgery and on the day of surgery. Bowel antibiotic treatment was continued for $72 \mathrm{~h}$. Follow ups were conducted in the hospital or on the phone, and reports were adopted from the hospital and other local hospitals.

\section{Surgical technique}

\section{Port placement and patient position}

A five-port transperitoneal approach is shown in Figure 1. A $12 \mathrm{~mm}$-camera port was placed $2 \mathrm{~cm}$ above the umbilicus, and the remaining ports were placed in view of the camera. Pneumoperitoneum was set at $12-15 \mathrm{mmHg}$. Two $8 \mathrm{~mm}-$ robotic ports were placed symmetrically $1 \mathrm{~cm}$ below the umbilicus level lateral to the rectus abdominis. One $12 \mathrm{~mm}$-assistant port was placed at the perpendicular bisector of one robotic port and the camera port, below the rib margin. Another $12 \mathrm{~mm}$-assistant port was placed at the position where the left anterior axillary line intersects with the umbilical horizontal line. The patient was first placed in steep $30^{\circ}$ Trendelenburg position and then adjusted almost horizontally $\left(0^{\circ}-5^{\circ}\right)$, contributing to the performance of tension-free urethral-neobladder anastomosis and helping to keep the small bowel contents in the epigastrium. A $0^{\circ}$ lens was used throughout the procedure. The first robotic arm was connected with monopolar scissors and the second arm with fenestrated bipolar forceps.

\section{RARC}

The ureters were identified at the bifurcation of the iliac artery and separated to the ureterovesical junction. The distal ends were clipped with Hem-o-Lok clips (Teleflex Medical, Morrisville, NC, USA) and cut. The distal ureteric margins were sent for frozen-section analysis. A transverse incision was performed in the rectovesical peritoneum exposing seminal vesicles and vas deferens, which were then completely divided and spared on the bladder. The subsequent procedures were similar to those for laparoscopic prostatectomy. Another transverse incision was performed in the Denonvilliers' fascia and extended to the 


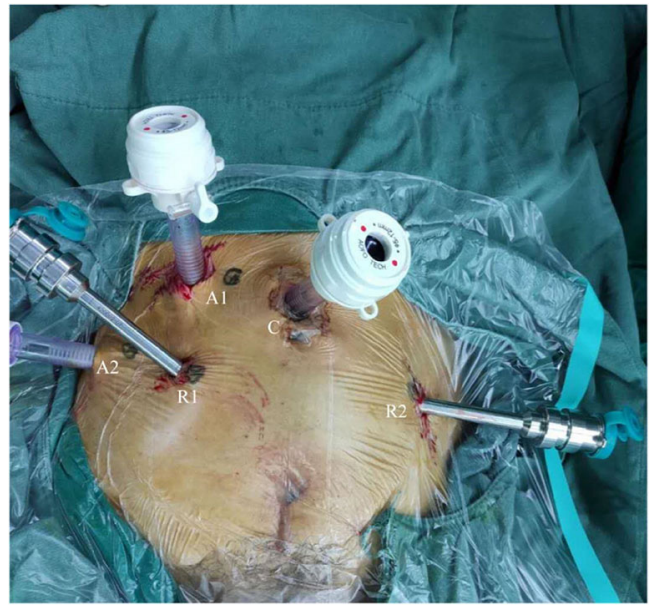

Figure 1 Port placement sites. C, camera; R, robotic; A, assistant.

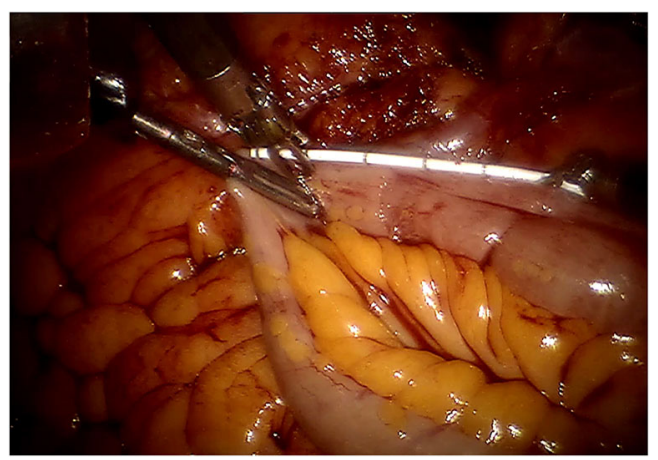

Figure 2 Selection of 50-cm terminal ileum segment with a graduated ureteral catheter.

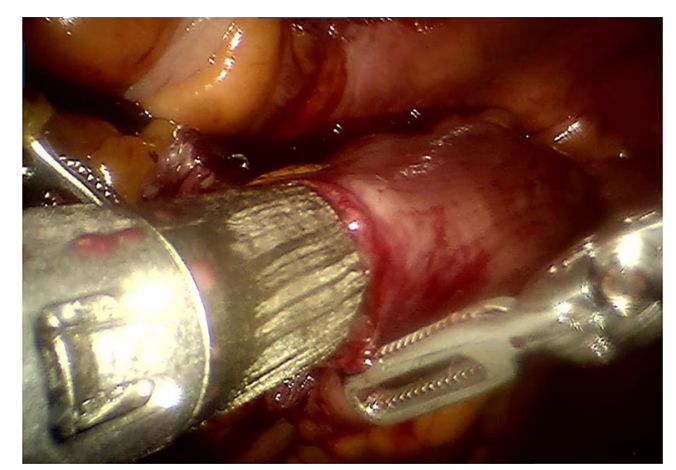

Figure 3 Side-to-side anastomosis for bowel continuity restoration. prostatic apex. Retzius' space was opened and dissections were conducted between the bladder walls and the pelvic lateral wall. Pubicoprostatic ligament was cut off at the reflection of pelvic fascia.

The dorsal venous plexus complex was detached with the help of cold scissors, and one 2-0 polyglactin 910 suture (VICRYL Plus; Ethicon Inc, Somerville, NJ, USA) was placed to control the bleeding. The urethra was detached at the prostatic apex. The segregated specimen was intactly carried into a specimen bag and placed into the abdominal cavity. The urethral margin was sent for frozen-section analysis.

\section{PLND}

Six patients accepted the standard PLND following RARC. The PLND included the area along the internal and external iliac vessels. Clearing was also applied to the lymph nodes and fat surrounding the obturator nerve. The proximal lymph nodes reached to the common iliac bifurcation, while the distal ones were close to the sacrum. The lateral border of the clearing area was the genitofemoral nerve.

\section{Bowel isolation and reconstruction}

The $50 \mathrm{~cm}$-terminal ileum segment was selected for the construction of the neobladder, approximately $20 \mathrm{~cm}$ proximal to the ileocecal junction. A graduated ureteral catheter was used to measure the ileum segment (Figure 2). Then, 2-0 polyglactin 910 sutures were used to mark the ends of the ileum segment and help manipulate the bowel. A $60 \mathrm{~mm}$-intestinal stapler (Endo-GIA; Ethicon LLC, San Lorenzo, Puerto Rico, USA) stapler was introduced into the enterocoelia and placed vertically across the ileum, separating the ileum segment and segmental mesentery. Then, the mesentery was further incised with monopolar scissors. The small bowel continuity was restored by performing side-to-side stapled anastomosis (Figure 3). Then, another stapler was introduced into the bowel to conduct anastomosis, with 2-0 polyglactin 910 sutures facilitating bowel traction. The remaining open ends of the bowel were closed with continuous 2-0 polyglactin 910 sutures, and interrupted sutures were placed if necessary. The antimesenteric boarders of the proximal and distal bowel ends must be identical to each other to maximumly restore small bowel function. Tension was not allowed for fear of postoperative bowel leakage.

Formation of neobladder and urethra-ileal anastomosis The $10-\mathrm{cm}$ proximal ileum segment remained intact as an 


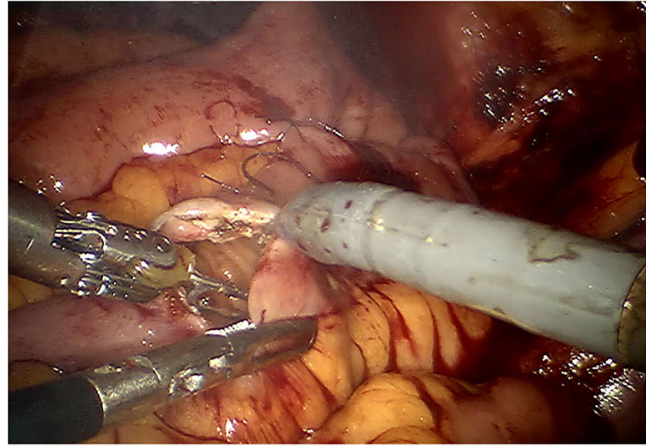

Figure 4 Detubularization of the ileum segment.

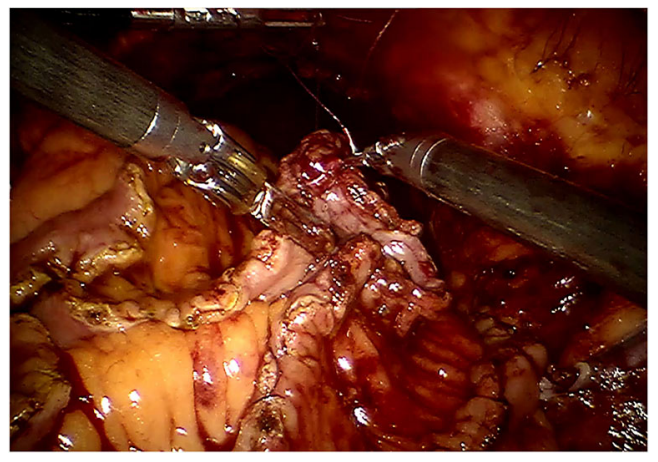

Figure 5 Posterior wall anastomosis firstly.

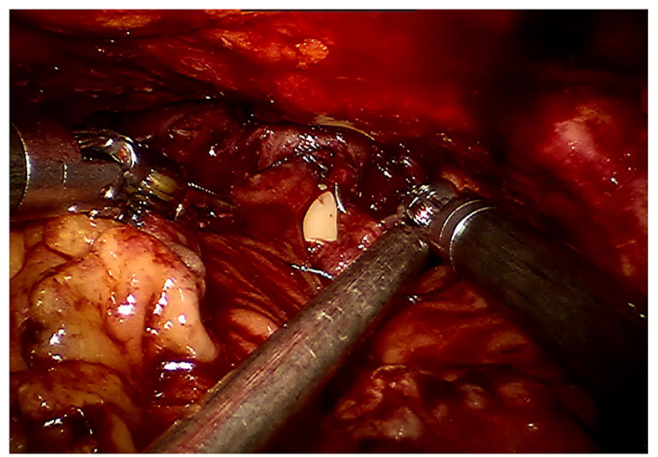

Figure 6 Urethra-ileal anastomosis at the start of anterior wall anastomosis.

afferent limb, and the remaining segment was arranged in a U-shape and detubularized along the antimesenteric locus with monopolar scissors (Figure 4). Then, 2-0 polyglactin 910 sutures were used to keep the U-shape of the ileum segment.

The posterior wall of the neobladder was first closed along the inner opposite borders with a continuous 3-0 VLoc anastomotic suture (Surgical Specialties Corporation,

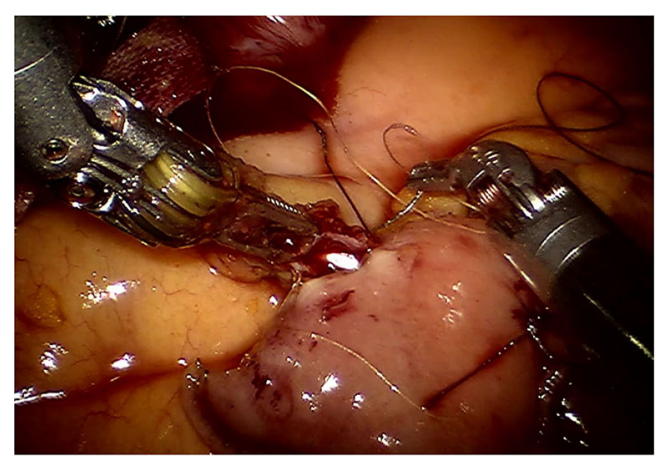

Figure 7 Anastomoses between ureters and afferent limb.

Massachusetts, USA, Figure 5). Afterwards, the ileum segment was pulled into the deep pelvis, which was required to reduce the tension of urethra-ileal anastomosis and ensure that the neobladder was at a proper position. At the bottom of the U-shaped ileum segment, urethraileal anastomosis was performed over a $16 \mathrm{~F}$ catheter with continuous 2-0 polyglactin 910 sutures (Figure 6). Then, an identical procedure as that in the posterior wall was repeated on the outer borders to close the anterior wall. However, a $2-\mathrm{cm}$ aperture was left on the anterior wall to help place the JJ ureteric stents after.

\section{Bilateral uretero-ileal anastomoses}

The ureters were spatulated for $1.5 \mathrm{~cm}$ and Bricker technique was selected for uretero-ileal anastomoses with continuous 4-0 polydioxanone sutures (Surgical Specialties Corporation, Massachusetts, USA). Before the anastomoses were completed, two $40 \mathrm{~cm}-\mathrm{JJ}$ ureteric stents were inserted into the bilateral ureters under the guidance of a guide wire. The stents were pulled through the afferent limb by using fenestrated forceps and pushed down into the neobladder via the aperture left on the anterior wall. The ureters were sequentially sutured to the afferent limb (Figure 7). The opening part of the neobladder was closed using 3-0 V-Loc anastomotic suture. The neobladder was then irrigated to check for leakage. If leakage were observed, extra sutures would have to be considered. A $20 \mathrm{~F}$ passive drain was placed in the pelvis through one of the ports. The experiment was carried out using the expanding incision of assistant port A1.

\section{Postoperative management}

The neobladder was irrigated every 8 hours from day 1 after the operation. The drain was removed when fluid was $<150 \mathrm{~mL} /$ day and the creatinine of the fluid was measured 
Table 1 Patient characteristics

\begin{tabular}{|c|c|}
\hline Variable & Value \\
\hline Patients, $n$ & 12 \\
\hline Gender, male, n (\%) & $12(100.0)$ \\
\hline Age, years, mean $\pm S D$ & $54.9 \pm 10.4$ \\
\hline $\mathrm{BMI}, \mathrm{kg} / \mathrm{m}^{2}$, mean $\pm \mathrm{SD}$ & $24.8 \pm 2.5$ \\
\hline \multicolumn{2}{|l|}{ ASA score, n (\%) } \\
\hline 1 & $2(16.7)$ \\
\hline 2 & $10(83.3)$ \\
\hline Creatinine, $\mu \mathrm{mol} / \mathrm{L}$, mean $\pm \mathrm{SD}$ & $70.1 \pm 15.7$ \\
\hline $\begin{array}{l}\text { Preoperative eGFR }{ }^{\mathrm{CKD}-\mathrm{EPI}}, \mathrm{mL} / \mathrm{min} / 1.73 \mathrm{~m}^{2} \text {, mean } \\
\pm \mathrm{SD}\end{array}$ & $100.3 \pm 14.3$ \\
\hline Preoperative hemoglobin, $\mathrm{g} / \mathrm{dL}$, mean $\pm \mathrm{SD}$ & $14.0 \pm 1.2$ \\
\hline \multicolumn{2}{|l|}{ Clinical T stage, n (\%) } \\
\hline Organ confined ( $\leq \mathrm{T} 2)$ & $11(91.7)$ \\
\hline Non-organ confined (> T2) & $1(8.3)$ \\
\hline Neoadjuvant chemotherapy, n (\%) & $2(16.7)$ \\
\hline \multicolumn{2}{|l|}{ Smoking history, n (\%) } \\
\hline$<10$ pack-years & $10(83.3)$ \\
\hline$\geq 10$ pack-years & $2(16.7)$ \\
\hline
\end{tabular}

BMI, body mass index; ASA, American Society of Anesthesiologists; eGFR $^{\text {CKD-EPI }}$, estimated glomerular filtration rate calculated using the 2009 Chronic Kidney Disease Epidemiology Collaboration (CKD-EPI) equation; SD, standard deviation.

to exclude urinary leakage. The catheter was removed routinely between 2 and 3 weeks. The ureteric stents were taken routinely at 4 weeks. Postponing was adopted if the patient had severe urinary tract infection.

\section{Outcome measures}

The patient characteristics were gender, age, BMI, American Society of Anesthesiologists score, smoking history, preoperative eGFR, preoperative hemoglobin, Clinical $\mathrm{T}$ stage, and neoadjuvant chemotherapy rate. The perioperative parameters included operative time, estimated blood loss, perioperative transfusion rate, postoperative bowel function, and hospital stay. The pathologic outcomes were $\mathrm{T}$ stage, lymph node and surgical margin status, lymph node yield, and incidental prostate adenocarcinoma rate. Postoperative complications were also recorded in accordance with the
Table 2 Perioperative parameters

\begin{tabular}{lc}
\hline Variable & Value \\
\hline Operative time, min, median (range) & $419(315-640)$ \\
Estimated blood loss, mL, median (range) & $400(250-1.200)$ \\
Perioperative transfusion, n (\%) & $8(66.7)$ \\
Time to flatus, days, median (range) & $3(2-5)$ \\
$\begin{array}{l}\text { Time to bowel function recovery, days, median } \\
\text { (range) }\end{array}$ & $5.5(3-7)$ \\
Hospital stay, days, median (range) & $14.5(9-25)$ \\
\hline $\begin{array}{l}\text { Adapted from tables in the publication: https://bjui-journals. } \\
\text { onlinelibrary. wiley.com/doi/full/10.1111/bju.13189, with } \\
\text { permission from John Wiley and Sons. }\end{array}$
\end{tabular}

Clavien-Dindo system (13). As for functional outcomes, continence at 6 and 12 months, clean intermittent selfcatheterization rate, and potency rate were assessed. Renal function was represented by the latest eGFR.

\section{Statistical analysis}

Statistical analysis was performed on SPSS version 26 (IBM Corp., Armonk, NY, USA). Continuous variables were expressed as means \pm standard deviation or medians and range (minimum-maximum). Categorical variables were expressed as frequencies and proportions. Survival data were expressed as median. The overall renal function was assessed using paired $t$ test, and $\mathrm{P}<0.05$ was considered statistically significant.

\section{Results}

A total of 12 male patients successfully underwent RARC with totally intracorporeal neobladder diversion without open conversion. Table 1 lists the characteristics of these patients. Their median age and BMI were 54.9 years and $24.8 \mathrm{~kg} / \mathrm{m}^{2}$, respectively. One patient $(8.3 \%)$ had clinical stage T3 and two (16.7\%) received neoadjuvant chemotherapy. The median operative time was $419 \mathrm{~min}$ (range, 315-640 min). Perioperative blood transfusion was administered in eight patients (66.7\%, Table 2).

Nine patients were confirmed having an organconfined disease $(\leq$ pT2) by surgical pathology. Adjuvant chemotherapy was offered to two patients who had pT3b stage. No positive surgical margins nor metastatic lymph nodes were noted. The median follow-up time was 
Table 3 Pathologic and oncologic outcomes

\begin{tabular}{|c|c|}
\hline Variable & Value \\
\hline \multicolumn{2}{|l|}{ Pathologic T stage, n (\%) } \\
\hline рT0 & $2(16.7)$ \\
\hline CIS & 0 \\
\hline $\mathrm{pTa}$ & $1(8.3)$ \\
\hline pT1 & $5(41.7)$ \\
\hline pT2a & $1(8.3)$ \\
\hline pT2b & 0 \\
\hline рT3a & $1(8.3)$ \\
\hline pT3b & $2(16.7)$ \\
\hline Organ confined ( $\leq \mathrm{pT} 2)$ & $9(75.0)$ \\
\hline Non-organ confined (> pT2) & $3(25.0)$ \\
\hline \multicolumn{2}{|l|}{ Lymph node status, n (\%) } \\
\hline pNO & $6(50.0)$ \\
\hline pN1-2 & 0 \\
\hline $\mathrm{pNx}$ & $6(50.0)$ \\
\hline Lymph node yield, $n$, median (range) & $11.5(8-21)$ \\
\hline Positive surgical margin, n (\%) & 0 \\
\hline Incidental prostate adenocarcinoma, n (\%) & $1(8.3)$ \\
\hline Follow-up time, months, median (range) & $13.1(5.4-32.0)$ \\
\hline
\end{tabular}

13.1 months (range, 5.4-32.0 months), and two patients died due to metastasis after 17 and 22 months (Table 3). One patient was diagnosed with pT3b stage and received gemcitabine and cisplatin chemotherapy. Fourteen months after the surgery, this patient exhibited abdominal metastasis, as shown in computed tomography, and gave up treatment and died at the 17 th month. Another patient was diagnosed with pT3a stage. Thirteen months after the surgery, this patient exhibited pelvic and sacrum metastasis, and gemcitabine and cisplatin chemotherapy was adopted. Programmed death-1 immunotherapy and docetaxel chemotherapy were used later. Extensive abdominal metastasis was confirmed by laparotomy at the 22nd month.

All complications in accordance with the ClavienDindo system are listed in Table 4. Early (0-30 days) complications occurred in six patients $(50.0 \%)$, while late (>30 days) complications occurred in five $(41.7 \%)$. One early case developed acute urinary retention with urinary tract infection, further developing into sepsis. Cystoscopic
Table 4 The early (0-30 days) and late ( $>30$ days) complications

\begin{tabular}{|c|c|c|}
\hline Complication & \multicolumn{2}{|c|}{$\begin{array}{c}\text { Early (0-30 days), Late (>30 days), } \\
\mathrm{n}(\%)\end{array}$} \\
\hline Overall & $6(50.0)$ & $5(41.7)$ \\
\hline \multicolumn{3}{|l|}{ Infection } \\
\hline UTI & $3(25.0)$ & $2(16.7)$ \\
\hline Pneumonia & $1(8.3)$ & \\
\hline \multicolumn{3}{|l|}{ Surgical } \\
\hline Urinary leak & $2(16.7)$ & \\
\hline Pelvic collection & $1(8.3)$ & \\
\hline \multicolumn{2}{|c|}{ Uretero-ileal anastomotic stricture } & $2(16.7)$ \\
\hline Acute urinary retention & $1(8.3)$ & $1(8.3)$ \\
\hline \multicolumn{3}{|l|}{ Gastrointestinal } \\
\hline lleus & $2(16.7)$ & $1(8.3)$ \\
\hline Diarrhoea/vomiting & $2(16.7)$ & \\
\hline Vitamin B12 deficiency & & $1(8.3)$ \\
\hline Wounds & 0 & 0 \\
\hline Cardiac/neurological & 0 & 0 \\
\hline Thromboembolic & 0 & 0 \\
\hline $\begin{array}{l}\text { Readmission due to } \\
\text { complications }\end{array}$ & $1(8.3)$ & $2(16.7)$ \\
\hline \multicolumn{3}{|c|}{ Grade of complication according to Clavien system } \\
\hline $\begin{array}{l}\text { Minor complication } \\
\text { (Grade 1-2) }\end{array}$ & 11 & 6 \\
\hline $\begin{array}{l}\text { Major complication } \\
\text { (Grade 3-5) }\end{array}$ & 1 & 1 \\
\hline
\end{tabular}

UTI, urinary tract infection. Adapted from tables in the publication: https://bjui-journals.onlinelibrary.wiley.com/doi/ full/10.1111/bju.13189, with permission from John Wiley and Sons.

urography was performed after effective anti-infectious treatment, but no tumor recurrence nor significant obstruction factors were observed. Late complications included two left uretero-ileal anastomotic strictures, with one requiring ureter reimplantation and another regular follow-up observation.

The daytime and nighttime continence at 6 months after surgery were $90.0 \%$ and $80.0 \%$, respectively (Table 5). Renal function was evaluated using the latest eGFR, and all 10 patients alive had eGFR $>60 \mathrm{~mL} / \mathrm{min} / 1.73 \mathrm{~m}^{2}$. No significant change in the overall renal function was noted 
Table 5 Functional outcomes

\begin{tabular}{|c|c|}
\hline Variable & Value \\
\hline \multicolumn{2}{|l|}{ Daytime continence, $\mathrm{n}(\%)^{\dagger}$} \\
\hline 6-month & $9(90.0)$ \\
\hline 12-month & $7(100.0)$ \\
\hline \multicolumn{2}{|l|}{ Nighttime continence, $\mathrm{n}(\%)^{\dagger}$} \\
\hline 6-month & $8(80.0)$ \\
\hline 12-month & $7(100.0)$ \\
\hline Clean intermittent self-catheterization, $\mathrm{n}(\%)$ & 0 \\
\hline Potency, n (\%) & $2(16.7)$ \\
\hline Latest eGFR ${ }^{\mathrm{CKD}-\mathrm{EPI}}, \mathrm{mL} / \mathrm{min} / 1.73 \mathrm{~m}^{2}$, mean $\pm \mathrm{SD}^{\ddagger}$ & $92.4 \pm 18.2$ \\
\hline
\end{tabular}

$(\mathrm{P}>0.05)$. However, one patient had an eGFR decline of $41.9 \%$, which may be explained by the uretero-ileal anastomotic stricture.

\section{Discussion}

At present, RARC has been adopted as a viable and safe alternative treatment for muscle-invasive high-risk noninvasive bladder cancer (1). Considering technique complexity and time consumption, extracorporeal urinary diversion is preferred in most cases, especially if a neobladder is chosen (3). Indeed, the intracorporeal approach is considered due to potential benefits of reduced pain, decreased bowel exposure, and reduced risk of fluid imbalances (14). A recent large single-institution comparison study confirmed that intracorporeal urinary diversion was associated with decreased 30 - and 90 -day major complication rates versus extracorporeal urinary diversion (15).

An ideal reservoir usually ought to have adequate capacity for storage and low pressure to preserve renal function. High compliance for continence and voluntary emptying without remarkable residual urine are also essential $(16,17)$. While a gold standard for neobladder configuration has not been established, several centers described their techniques for creating an intracorporeal ileal neobladder. The Studer neobladder is the most commonly performed type of ileal neobladder $(18,19)$. Tan et al. (9) reported their technique of pyramid neobladder. The Y-pouch was also adopted in some centers $(20,21)$. An intracorporeal $\mathrm{W}$-pouch from Hussein et al. was recently described (6).
Operative time is a significant aspect worth considering by surgeons. Multivariable analysis of one latest study including 948 patients with radical cystectomy revealed that operative time was an independent risk factor of increased 90-day major complications (15). Jonsson et al. (14) reported a median operative time of $480 \mathrm{~min}$ (range: $330-760$ ), while an improved outcome of $5 \mathrm{~h}$ (range: $3.5-8.0$ ) was presented by Tan et al. (9). Moreover, several studies have confirmed that several perioperative indicators, including operative time, could be optimized with increasing experience $(14,22,23)$. Chopra et al. (10) reported their technical improvements resulting in an improvement in the mean operative time from 450 to $360 \mathrm{~min}$. The perioperative outcomes in the present study were almost comparable to those in previous literatures except for longer hospital stay $(9,14)$, which could be expected give that the authors' experience of RARC with intracorporeal neobladder was at an early stage and sufficient caution seemed necessary. This finding could be improved with increasing cases of intracorporeal neobladder.

Oncologic outcomes are good tools for evaluating the effectiveness and risks of treatment. In an analysis of 99 patients with follow up $>5$ years, pathologic stage, lymph node stage, and margin status were each significantly associated with recurrence-free survival and overall survival (24). Yuh et al. (25) similarly found that 5 -year survival was worse with higher pathologic stage or lymph node positivity $(\mathrm{P}<0.01)$. In the present study, three patients $(25.0 \%)$ were $>$ pT2, and no lymph node nor margin involvement was found.

As for complications, the risk of intraoperative complications is usually low but postoperative complications are common. A systematic review demonstrated that following RARC, the median early and late major complication rates were $24 \%$ (range: $0-54 \%$ ) and $20 \%$ (range: $0-23 \%$ ), respectively, in extracorporeal neobladder diversion series and 28\% (range: $15-33 \%$ ) and $18 \%$ (range: $12-21 \%$ ), respectively, in intracorporeal approach (26). The complication rates in the present study were covered in the data range. Moreover, the risk of complications may be associated with many factors, including age, BMI, renal function, comorbidity, urinary approach, and operative time (26).

Postoperative functional outcomes considerably affect the quality of life of patients. The continence results in the present study were $90.0 \%$ for daytime and $80.0 \%$ for nighttime at 6 months, but both reached an excellent rate of $100 \%$ at 12 months, which was similar with those reported in other studies (14). The potency rate was inferior to 
that in a previous report (27). In view of the principle of radical cure of malignant tumor, nerve preservation was not adopted in this series. Jonsson et al. (14) reported a potency rate of $93.8 \%$ in 20 male cases with bilateral nervesparing surgery. Tuderti et al. (28) reported that eight out of 11 female patients $(72.7 \%)$ were sexually active at the 12 -month evaluation. In this regard, nerve-sparing surgery is attractive, and it will be gradually conducted in the future work. As for renal function, most patients receiving neobladder substitution could maintain long-term renal function, while $3.8 \%$ of cases had increased serum creatinine levels. Uretero-ileal anastomotic stricture was the most common cause of renal function impairment (29). Tan et al. (9) reported the outcome of eight patients (out of 20) with reduction in eGFR $>10 \mathrm{~mL} / \mathrm{min} / 1.73 \mathrm{~m}^{2}$ postoperatively. No significant renal function change was observed in the present study, with a median follow up of 13.1 months. A notable details that studies evaluating renal function are limited, and optimal evaluative endpoints must be proposed and verified (29-31).

Based on the experience of the authors, the following aspects could improve the quality and efficiency of intracorporeal neobladder construction. First, long enough bowels must be ensured to make a reservoir and keep an eye on mesenteric arch to preserve adequate blood supply. Second, assistant sutures must be placed to mark and help manipulate bowels, such as restoring intestinal continuity and fixing the U-shape. Third, a guided duct seems unnecessary during detubularization. Besides, the urethra could be anastomosed with the farthest point of anterior wall instead of a new incision, thereby reducing the risk of urethra-ileal anastomotic leakage and stricture. Finally, a practiced and cooperative robotic team is essential for this complicated procedure.

This report has several limitations. The small sample size and short follow up are obvious weaknesses. Considering the complexity and challenge of the intracorporeal ileal neobladder technique, intense caution was exercised during the initial stage. The vast majority of patients chose traditional urinary diversion on abdominal wall rather than this technique. A longer follow up is required for improved evaluation of the prognosis. Besides, an enhanced recovery after surgery could be conducted to improve the outcomes. Bias may be present on patient selection due to filtration of external medical institutions. PLND was not performed in some patients diagnosed with non-advanced cancer. Though no evidence of lymph node invasion was found through preoperative imaging examination, intraoperative vision and follow up, surgery without PLND may cause some patients to lose potential oncological benefit. Urodynamic studies and quality-of-life outcomes were not reported. More cases and long-term and randomized controlled studies will be the focus in the future.

\section{Conclusions}

RARC with intracorporeal neobladder is a challenging but technically feasible procedure, with promising oncologic and functional outcomes. Given that intracorporeal neobladder involves the intestinal system, different from traditional urinary diversion, its efficacy must be further confirmed by long-term follow up and standardized evaluation.

\section{Acknowledgments}

Funding: None.

\section{Footnote}

Reporting Checklist: The authors have completed the STROBE reporting checklist. Available at http://dx.doi. org/10.21037/tau-20-1075

Data Sharing Statement: Available at http://dx.doi. org/10.21037/tau-20-1075

Peer Review File: Available at http://dx.doi.org/10.21037/ tau-20-1075

Conflicts of Interest: All authors have completed the ICMJE uniform disclosure form (available at http://dx.doi. org/10.21037/tau-20-1075). The authors have no conflicts of interest to declare.

Ethical Statement: The authors are accountable for all aspects of the work in ensuring that questions related to the accuracy or integrity of any part of the work are appropriately investigated and resolved. All research procedures were conducted in accordance with the Declaration of Helsinki (as revised in 2013). This study was approved by the Ethics Committee of The First Affiliated Hospital of Nanjing Medical University (No. 2020-SR207), and informed consent was taken from all the patients.

Open Access Statement: This is an Open Access article 
distributed in accordance with the Creative Commons Attribution-NonCommercial-NoDerivs 4.0 International License (CC BY-NC-ND 4.0), which permits the noncommercial replication and distribution of the article with the strict proviso that no changes or edits are made and the original work is properly cited (including links to both the formal publication through the relevant DOI and the license). See: https://creativecommons.org/licenses/by-nc$\mathrm{nd} / 4.0 \%$.

\section{References}

1. Witjes JA, Bruins HM, Cathomas R, et al. European Association of Urology Guidelines on Muscle-invasive and Metastatic Bladder Cancer: Summary of the 2020 Guidelines. Eur Urol 2021;79:82-104.

2. Leow JJ, Reese SW, Jiang W, et al. Propensitymatched comparison of morbidity and costs of open and robot-assisted radical cystectomies: a contemporary population-based analysis in the United States. Eur Urol 2014;66:569-76.

3. Ahmed K, Khan SA, Hayn MH, et al. Analysis of intracorporeal compared with extracorporeal urinary diversion after robot-assisted radical cystectomy: results from the International Robotic Cystectomy Consortium. Eur Urol 2014;65:340-7.

4. Brown $M$, Challacombe B. Intracorporeal urinary diversion after robot-assisted cystectomy: time to climb the next learning curve? Eur Urol 2014;65:348-9.

5. Hautmann RE, Herr HW, Pruthi RS, et al. Robotic radical cystectomy--is the diversion the Achilles' heel? J Urol 2014;192:1601-3.

6. Hussein AA, Ahmed YE, Kozlowski JD, et al. Robotassisted approach to ' $\mathrm{W}$ '-configuration urinary diversion: a step-by-step technique. BJU Int 2017;120:152-7.

7. Pruthi RS, Nix J, McRackan D, et al. Robotic-assisted laparoscopic intracorporeal urinary diversion. Eur Urol 2010;57:1013-21.

8. Goh AC, Gill IS, Lee DJ, et al. Robotic intracorporeal orthotopic ileal neobladder: replicating open surgical principles. Eur Urol 2012;62:891-901.

9. Tan WS, Sridhar A, Goldstraw M, et al. Robotassisted intracorporeal pyramid neobladder. BJU Int 2015;116:771-9.

10. Chopra S, de Castro Abreu AL, Berger AK, et al. Evolution of robot-assisted orthotopic ileal neobladder formation: a step-by-step update to the University of Southern California (USC) technique. BJU Int
2017;119:185-91.

11. Minervini A, Vanacore D, Vittori G, et al. Florence robotic intracorporeal neobladder (FloRIN): a new reconfiguration strategy developed following the IDEAL guidelines. BJU Int 2018;121:313-7.

12. Simone G, Papalia R, Misuraca L, et al. Robotic Intracorporeal Padua Ileal Bladder: Surgical Technique, Perioperative, Oncologic and Functional Outcomes. Eur Urol 2018;73:934-40.

13. Mitropoulos D, Artibani W, Biyani CS, et al. Validation of the Clavien-Dindo Grading System in Urology by the European Association of Urology Guidelines Ad Hoc Panel. Eur Urol Focus 2018;4:608-13.

14. Jonsson MN, Adding LC, Hosseini A, et al. Robot-assisted radical cystectomy with intracorporeal urinary diversion in patients with transitional cell carcinoma of the bladder. Eur Urol 2011;60:1066-73.

15. Zhang JH, Ericson KJ, Thomas LJ, et al. Large Single Institution Comparison of Perioperative Outcomes and Complications of Open Radical Cystectomy, Intracorporeal Robot-Assisted Radical Cystectomy and Robotic Extracorporeal Approach. J Urol 2020;203:512-21.

16. Studer UE, Zingg EJ. Ileal orthotopic bladder substitutes. What we have learned from 12 years' experience with 200 patients. Urol Clin North Am 1997;24:781-93.

17. Hautmann RE, de Petriconi R, Gottfried HW, et al. The ileal neobladder: complications and functional results in 363 patients after 11 years of followup. J Urol 1999;161:422-7; discussion 427-8.

18. Thress TM, Cookson MS, Patel S. Robotic Cystectomy with Intracorporeal Urinary Diversion: Review of Current Techniques and Outcomes. Urol Clin North Am 2018;45:67-77.

19. Fahmy O, Asri K, Schwentner C, et al. Current status of robotic assisted radical cystectomy with intracorporeal ileal neobladder for bladder cancer. J Surg Oncol 2015;112:427-9.

20. Hassan AA, Elgamal SA, Sabaa MA, et al. Evaluation of direct versus non-refluxing technique and functional results in orthotopic Y-ileal neobladder after 12 years of follow up. Int J Urol 2007;14:300-4.

21. Butt ZA, Forbes E, Zorn J, et al. Robotic radical cystectomy with intracorporeal neobladder: Initial experience and outcomes. Can Urol Assoc J 2015;9:E156-9.

22. Hayn MH, Hussain A, Mansour AM, et al. The learning curve of robot-assisted radical cystectomy: results from the International Robotic Cystectomy Consortium. Eur Urol 2010;58:197-202. 
23. Schumacher MC, Jonsson MN, Hosseini A, et al. Surgery-related complications of robot-assisted radical cystectomy with intracorporeal urinary diversion. Urology 2011;77:871-6.

24. Raza SJ, Al-Daghmin A, Zhuo S, et al. Oncologic outcomes following robot-assisted radical cystectomy with minimum 5-year follow-up: the Roswell Park cancer institute experience. Eur Urol 2014;66:920-8.

25. Yuh B, Torrey RR, Ruel NH, et al. Intermediate-term oncologic outcomes of robot-assisted radical cystectomy for urothelial carcinoma. J Endourol 2014;28:939-45.

26. Novara G, Catto JW, Wilson T, et al. Systematic review and cumulative analysis of perioperative outcomes and complications after robot-assisted radical cystectomy. Eur Urol 2015;67:376-401.

27. Tyritzis SI, Hosseini A, Collins J, et al. Oncologic, functional, and complications outcomes of robot-assisted

Cite this article as: Gu Q, Xia J, Xu A, Zhang T, Wang Z. Robot-assisted radical cystectomy with totally intracorporeal neobladder diversion: perioperative, oncologic, and functional outcomes. Transl Androl Urol 2020;9(6):2606-2615. doi: 10.21037/ tau-20-1075 radical cystectomy with totally intracorporeal neobladder diversion. Eur Urol 2013;64:734-41.

28. Tuderti G, Mastroianni R, Flammia S, et al. Sex-Sparing Robot-Assisted Radical Cystectomy with Intracorporeal Padua Ileal Neobladder in Female: Surgical Technique, Perioperative, Oncologic and Functional Outcomes. J Clin Med 2020;9:577.

29. Minervini A, Serni S, Vittori G, et al. Current indications and results of orthotopic ileal neobladder for bladder cancer. Expert Rev Anticancer Ther 2014;14:419-30.

30. Harraz AM, Mosbah A, El-Assmy A, et al. Renal function evaluation in patients undergoing orthotopic bladder substitution: a systematic review of literature. BJU Int 2014;114:484-95.

31. Delanghe SE, Speeckaert MM, Delanghe JR. How to assess renal function in patients with a neobladder. Clin Chim Acta 2020;504:154. 